\title{
Identification and Isolation of Caffeic, Chlorogenic and Ferulic Acids in Aerial Parts of Capparis spinosa wildly grown in Iraq
}

Asmaa M. Hussein*,1 and Enas J. Kadum**

*Department of Pharmacognosy and Medicinal Plants, College of Pharmacy, University of Baghdad, Baghdad. Iraq.

\begin{abstract}
Capparis spinosa is one of the oldest genera grown in Iraqi territory with worldwide traditional medicinal uses beside the culinary uses. These uses were due to the presence of many phytochemicals including flavonoids and polyphenols. Among the reported polyphenolic acids were caffeic, chlorogenic and ferulic acids with wellknown and powerful antioxidant properties. The present work aimed to isolate and identify the presence of these polyphenolic acids in Iraqi Capparis spinosa (Iraqi caper) which is wildly grown in the middle areas following standard chromatographic procedures. Aerial parts of the plant (buds, berries and leaves) were extracted with hydroalcoholic solvent by maceration method. The extract was fractionated with chloroform, n-butanol and ethyl acetate. Thin layer chromatographic (TLC) techniques and high performance liquid chromatography (HPLC) analysis were performed to identify the presence of polyphenolic acids in the ethyl acetate fraction. The result obtained in this work showed the presence of these phenolic acids in the investigated extract. Chromatographic analysis revealed the presence of considerable amounts of these acids in ethyl acetate fraction when the separated spots were compared with Rf values and UV spectra of standards. Such data give a promising use of aerial parts of Iraqi caper for globally reported medicinal uses.
\end{abstract}

Keywords: Capparis spinosa, caffeic, chlorogenic, ferulic acids, identification.

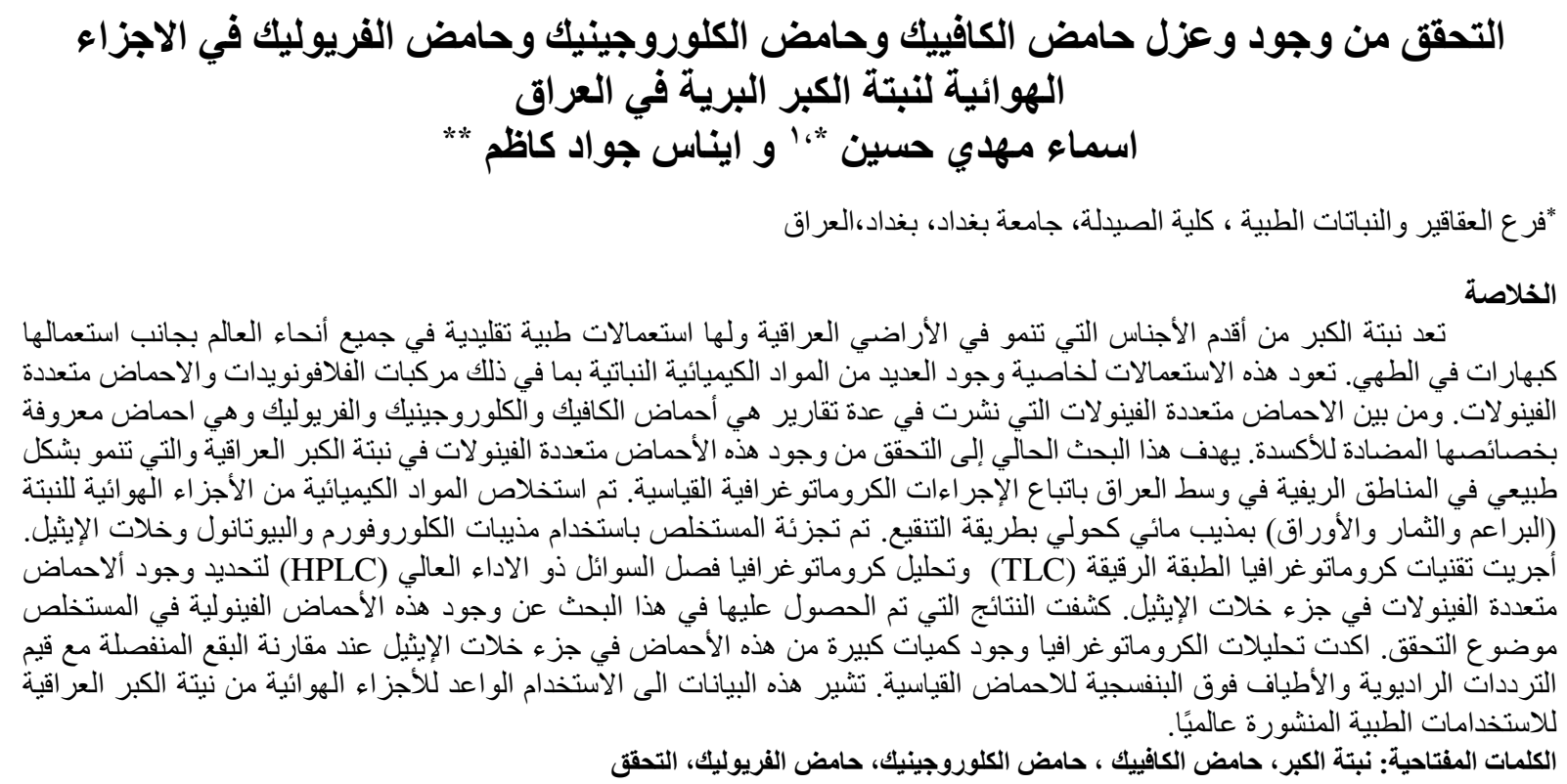

\section{Introduction}

Capparaceae or Capper family comprises world-wide 33-45 genera and 700 species (1). Capparis is one of the oldest genera of Capparaceae found in Asia ${ }^{(2)}$. The species spinosa was reported to grow naturally in open fields; erupt through cracks of rocks and stone walls in hot deserts and rural areas. It grows well in nutrient and water deprived semi-arid or arid soil. Iraq caper is called shefallah and the season of growth is extended from June to September at this time Capparis spinosa produce their ripe berries (3). Morphologically, genera of Capparis spinosa consist of leaves with apical spines, flower bud and spiny stems. The flowers buds then grow into berries which contain characteristic seeds (Figure 1) ${ }^{(4)}$. The plant is commonly used for its valuable culinary characteristics of its buds and berries owing to the presence of many constituents like capric acid, glucosinlates, isothiocyanate, mustard oil and phenols ${ }^{(5-8)}$.

${ }^{1}$ Corresponding author E-mail: asmaa.mahdi.d@gmail.com

Received: 4/ 3/ 2020

Accepted:12/7/2020

Iraqi Journal of Pharmaceutical Science 
Besides, the plant gained a famous use in medicine with medicinal uses as analgesic, antiarteriosclerotic, anti-cancer, anti-diabetic, antihemorrhoid, anti-infective, anti-rheumatic, diuretic, emetic, gout treatment, tonic, in addition to hepatoprotecive effects ${ }^{(6,9-11)}$. These activities are related to the presence of important pharmacologic constituents like alkaloids, flavonoids, glycosides, saponins, sterols, tannins, triterpenoids and vitamins (12).

Hydroxycinnamic acid is an abundant precursor phenolic acid in many plants including Capparis spinosa. This phytochemical is used for the biosynthesis of aromatic compounds by the plant ${ }^{(13)}$.

The antioxidant and photoprotecive properties of hydroxycinnamic acid was evaluated in the methanolic extracts of Capparis spinosa buds with a promising important application of this extract in topical cosmetic products employed in skin alteration ${ }^{(14)}$.

The present study aimed to detect the presence of polyphenolic acids in Iraqi Capparis spinosa grown in the middle of Iraq for the first time.

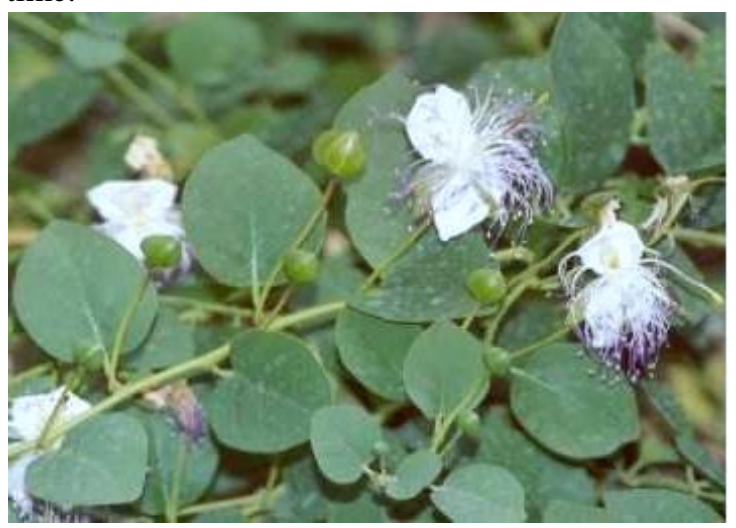

Figure 1. Iraqi Capparis spinosa

\section{Materials and Methods \\ Plant Material}

Aerial parts of Capparis spinosa (buds, berries and leaves) were collected from rural area in the middle of Iraq, Wasit province, Suwera district during summer (July and August) 2018. The plant was identified and authenticated by the University of Baghdad /College of Sciences/ Department of Biology by Prof. Dr. Sukaena Abass. Aerial parts used in this work were washed thoroughly with tap water, dried under shade, and grinded to yield a powder.

\section{Extraction of the plant}

About $700 \mathrm{gm}$ of the crude powder was defatted with $1 \mathrm{~L}$ of $\mathrm{n}$-hexane. The dried defatted material were soaked in $1 \mathrm{~L}$ of hydroalcoholic solvent (methanol:water, 80:20) for 3days with occasional shaking. The extract was filtered and few drops of it were used for preliminary phytochemical screening for the presence of phenolic acids. The filtered extract then evaporated under vacuum and about
$20 \mathrm{gm}$ of the residue were reconstituted with $500 \mathrm{ml}$ of water for partitioning with chloroform, n-butanol and ethyl acetate $(500 \mathrm{ml} \times 3$ times). Each layer then dried over anhydrous sodium sulfate, filtered and dried under vacuum rotary evaporator and the residue was analyzed by chromatographic techniques.

\section{Preliminary phytochemical screening of phenolic acids}

Few milligram of each extract were reconstituted with $10 \mathrm{ml}$ absolute ethanol, filtered and treated with few drops of 5\% (w/v) glacial acetic acid and 5\% (w/v) $\mathrm{NaNO}_{2}$ solution (Ellagic Acid Test). The presence of black brown precipitate indicates the presence of phenols ${ }^{(15)}$.

\section{Identification of phenolic acids by thin layer} chromatography

Few drops of standard caffeic, chlorogenic and ferulic acids ( $1 \mathrm{mg}$ in $1 \mathrm{ml}$ absolute methanol) and of suspended ethyl acetate fraction (1mg in $1 \mathrm{ml}$ absolute methanol) were applied to activated silica gel (Alugram Xtra SIL G/UV254) using chloroform:acetone:formic acid $(75: 16.5: 8.5)$ as a mobile phase. The plates were detected under 254nm UV lengths.

\section{Isolation of phenolic acids by preparative thin layer chromatography}

A handmade TLC plates (silica gel GF254, 20 $\times 20,0.75 \mathrm{~mm}$ thick) were prepared using TLC coater. These plates were activated thereafter at $120^{\circ} \mathrm{C}$ for 1 hour prior to sample application. About $1 \mathrm{mg}$ of ethyl acetate fraction was dissolved in $3 \mathrm{ml}$ absolute methanol and spotted as streaks over the prepared plates using capillary tube and allowed for development according to the standard procedures using butanol:acetic acid: water (40:10:50) as a mobile phase. The separated bands were detected under UV at $254 \mathrm{~nm}$ and marked with a needle. With the use of a fine spatula, the marked bands were scraped and collected in separated flasks. To each flask, an adequate quantity of absolute methanol was added with frequent shaking in warm water. After cooling, the mixture was filtered through double filter paper and the solvent was evaporated thereafter using vacuum rotary evaporator. The semisolid residue for each band was marked as $\mathrm{E}$ sample.

\section{Identification of phenolic acids by thin layer chromatography}

Few drops of standard phenolic acids (caffeic, chlorogenic and ferulic) and of samples E1 to E5 (1mg in $1 \mathrm{ml}$ absolute methanol) were applied to activated silica gel using chloroform: acetone: formic acid (75:16.5:8.5) as a mobile phase. The developed plated were detected under $254 \mathrm{~nm}$ and $366 \mathrm{~nm}$ UV and the $\mathrm{R}_{\mathrm{f}}$ values of separated spots were compared to those of standard phenolic acids. 


\section{Identification of phenolic acids by HPTLC analysis \\ Approximately, $2 \mu \mathrm{L}$ of $1 \mathrm{mg} / \mathrm{ml}$ methanolic} solution of each isolated sample and standard phenolic acids (caffeic, chlorogenic and ferulic) were applied to $20 \mathrm{~cm} \times 10 \mathrm{~cm}$ HPTLC plates (silica gel 60F254) using chloroform:acetone:formic acid $(75: 16.5: 8.5)$ as a mobile phase and scanned at $254 \mathrm{~nm}$ and $366 \mathrm{~nm}$.

Identification of phenolic acids by HPLC analysis

About $0.04 \mathrm{mg}$ of each of the isolated samples and of the standards phenolic acids (caffeic, chlorogenic and ferulic) is mixed with $1 \mathrm{~m}$ of HPLC grade methanol using vortex mixer. The mixtures filtered with $2.5 \mu \mathrm{m}$ disposable filter and run in HPLC machine using gradient of mobile phase

composed of solvent A ( $1 \%$ acetic acid in HPLC grade water) and solvent B (acetonitrile). The results were detected on wave lengths of 272, 280, 310nm.

\section{Results}

Preliminary and TLC analysis

The presence of phenolic acid in the ethyl acetate fraction was confirmed with the brown precipitate obtained by Ellagic acid test. TLC analysis of ethyl acetate fraction showed the separation of several spots some of them were matched with standard caffeic, chlorogenic and ferulic acids spots (Figure 2).

\section{Isolation of phenolic acids}

Elution of ethyl acetate fraction in chloroform: acetone: formic acid (75:16.5:8.5) results in several isolated bands on preparative TLC plates which were marked as E1, E2, E3, E4 and E5 samples (Figure 3).

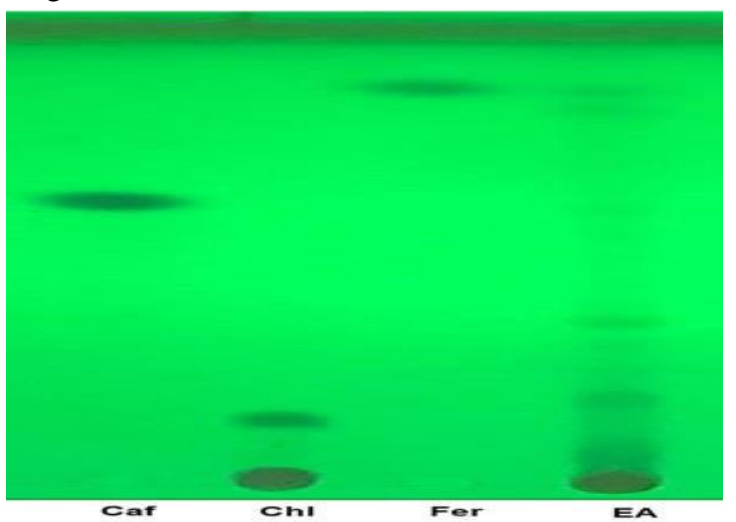

Figure 2. TLC plates for analyzed ethyl acetate fraction developed in the chloroform:acetone:formic acid $(75: 16.5: 8.5)$ at 254nm. (Caffeic acid, Chl= chlorogenic acid Fer=ferulic acid, EA=ethyl acetate fraction.
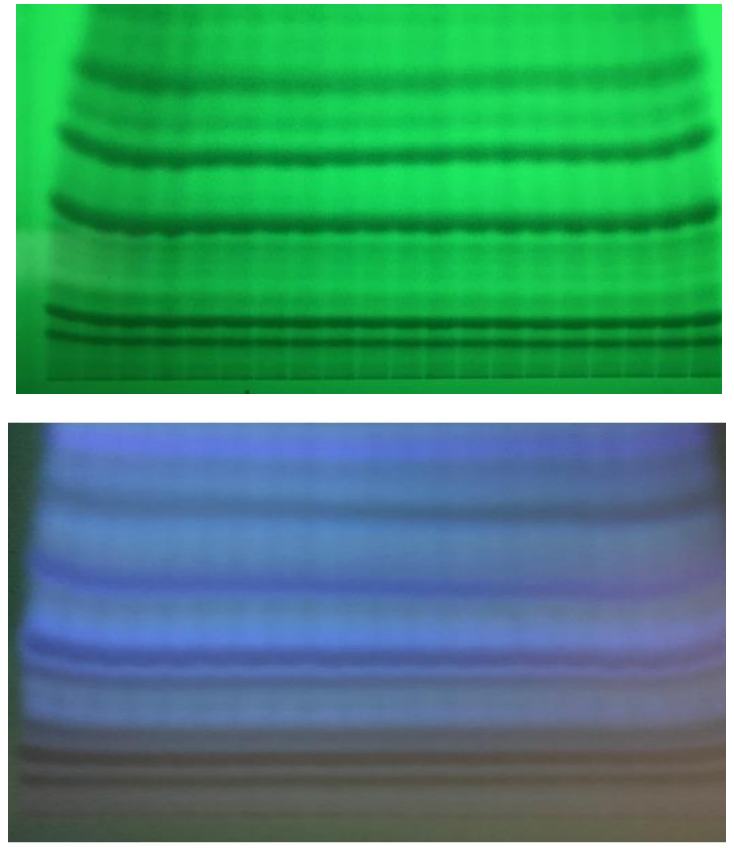

Figure 3. Preparative TLC plates of ethyl acetate fraction eluted in butanol:acetic acid:water (40:10:50) at 254nm (upper) and 366nm (lower).

\section{TLC analysis of isolated samples}

Analysis with TLC of samples E1 to E5 revealed the presence of caffeic, chlorogenic and ferulic acids in samples E3, E2 and E5, respectively with respective $R_{f}$ values of $0.58,0.12$ and 0.90 (Figure 4). The phenolic acid in each sample was assigned depending on the comparable $\mathrm{Rf}$ value of the corresponding standard phenolic acid in Table (1).

\section{HPTLC analysis of isolated samples}

The data obtained with HPTLC analysis of samples E1 to E5 confirms the results obtained with TLC analysis. Confirmation based on comparable $\mathrm{R}_{\mathrm{f}}$ values of the samples to that of standard phenolic acids in Table (2). HPTLC chromatograms for standard and samples phenolic acid were shown in Figures 5, 6 and 7 and HPTLC plates at 254nm and $366 \mathrm{~nm}$ were shown in Figure 8.

\section{Qualitative and quantitative HPLC analysis}

The presence of caffeic, chlorogenic and ferulic acids in Iraqi caper was also confirmed qualitatively and quantitatively by HPLC analysis according to the retention time of standard phenolic acids used. These phenolic acids were detected in samples E2, E3 and E5 according to the retention time of standard phenolic acids (Table 3). In this context, caffeic, chlorogenic and ferulic acids in sample E3, E2 and E5, respectively show similar UV spectra of standard phenolic acids (Figures 9, 10 and 11). 


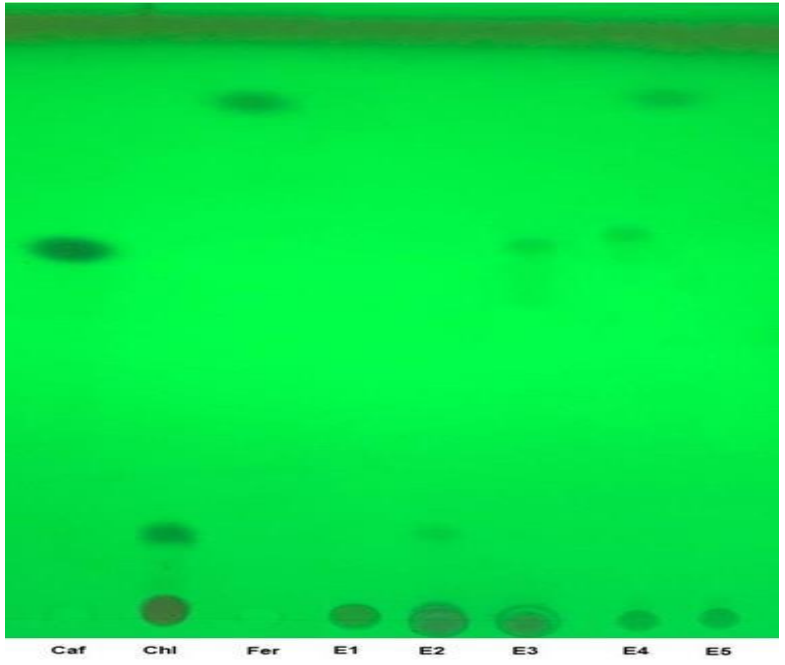

Figure 4. TLC plates for analyzed samples E1 to E5 developed in the Chloroform:acetone:formic acid $(75: 16.5: 8.5)$ at $254 \mathrm{~nm}$. (Fer=ferulic acid, $\mathbf{E A}=$ ethyl acetate fraction.
Table 1. Rf values of the standard and samples phenolic acids.

\begin{tabular}{||c|c|c|c||}
\hline $\begin{array}{c}\text { Phenolic } \\
\text { acid }\end{array}$ & $\begin{array}{c}\text { Standard } \\
\text { Rf }\end{array}$ & $\begin{array}{c}\text { Sample } \\
\text { Rf }\end{array}$ & Sample \\
\hline Caffeic acid & 0.61 & 0.58 & E3 \\
\hline $\begin{array}{l}\text { Chlorogenic } \\
\text { acid }\end{array}$ & 0.14 & 0.12 & E2 \\
\hline Ferulic acid & 0.89 & 0.90 & E5 \\
\hline
\end{tabular}

Table 2. Max $R_{f}$ values of the standard and samples phenolic acids.

\begin{tabular}{|l|c|c|c|c||}
\hline \hline Phenolic acid & $\begin{array}{c}\text { Standard } \\
\text { Rf }\end{array}$ & $\begin{array}{c}\text { Sample } \\
\text { Rf }\end{array}$ & $\begin{array}{c}\text { Area } \\
\%\end{array}$ & Sample \\
\hline Caffeic acid & 0.44 & 0.43 & 49.34 & E3 \\
\hline $\begin{array}{l}\text { Chlorogenic } \\
\text { acid }\end{array}$ & 0.04 & 0.03 & 47.64 & E2 \\
\hline Ferulic acid & 0.55 & 0.54 & 43.31 & E5 \\
\hline
\end{tabular}
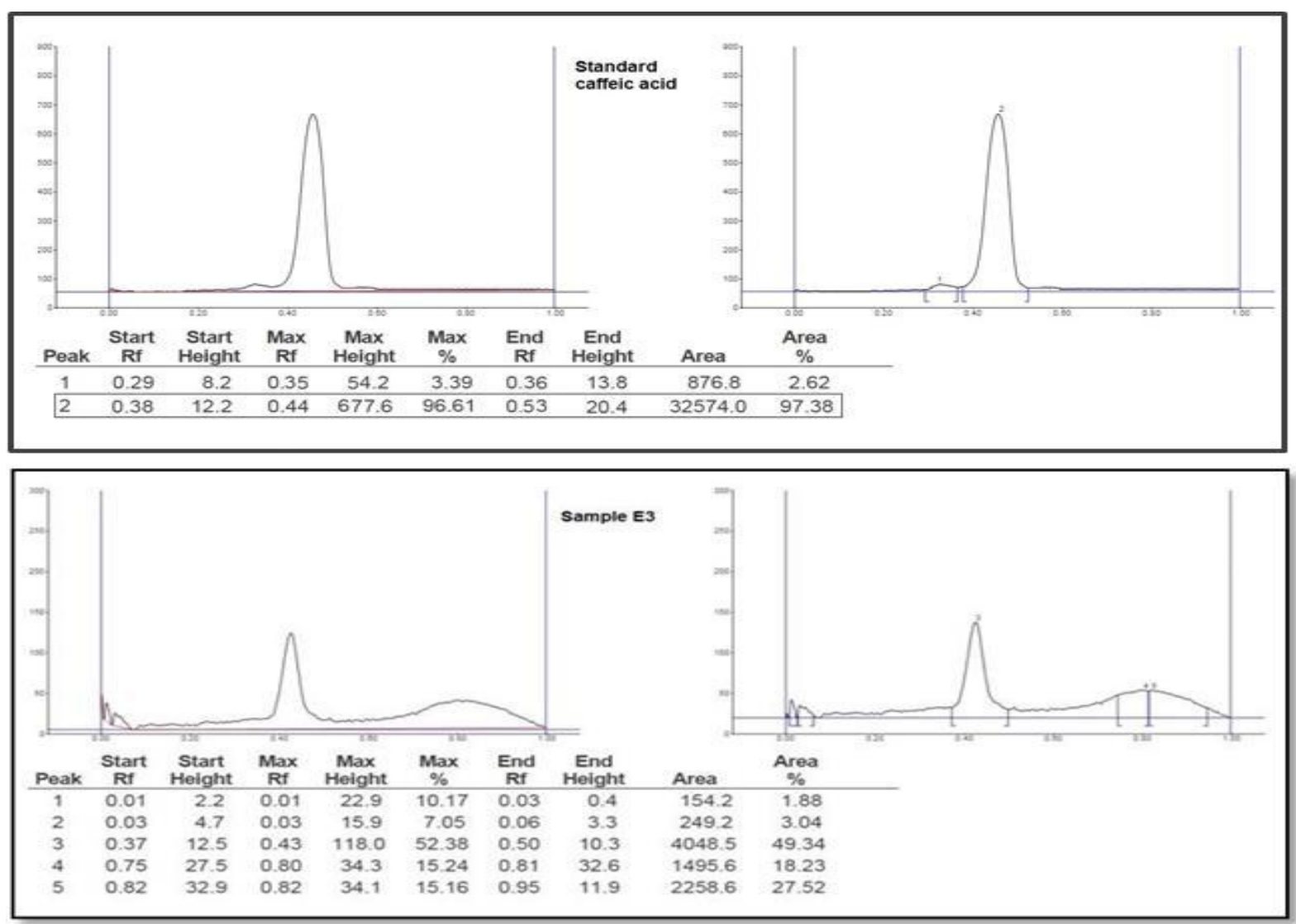

Figure 5. HPTLC chromatogram of standard and sample E3 caffeic acid at $254 \mathrm{~nm}$ 

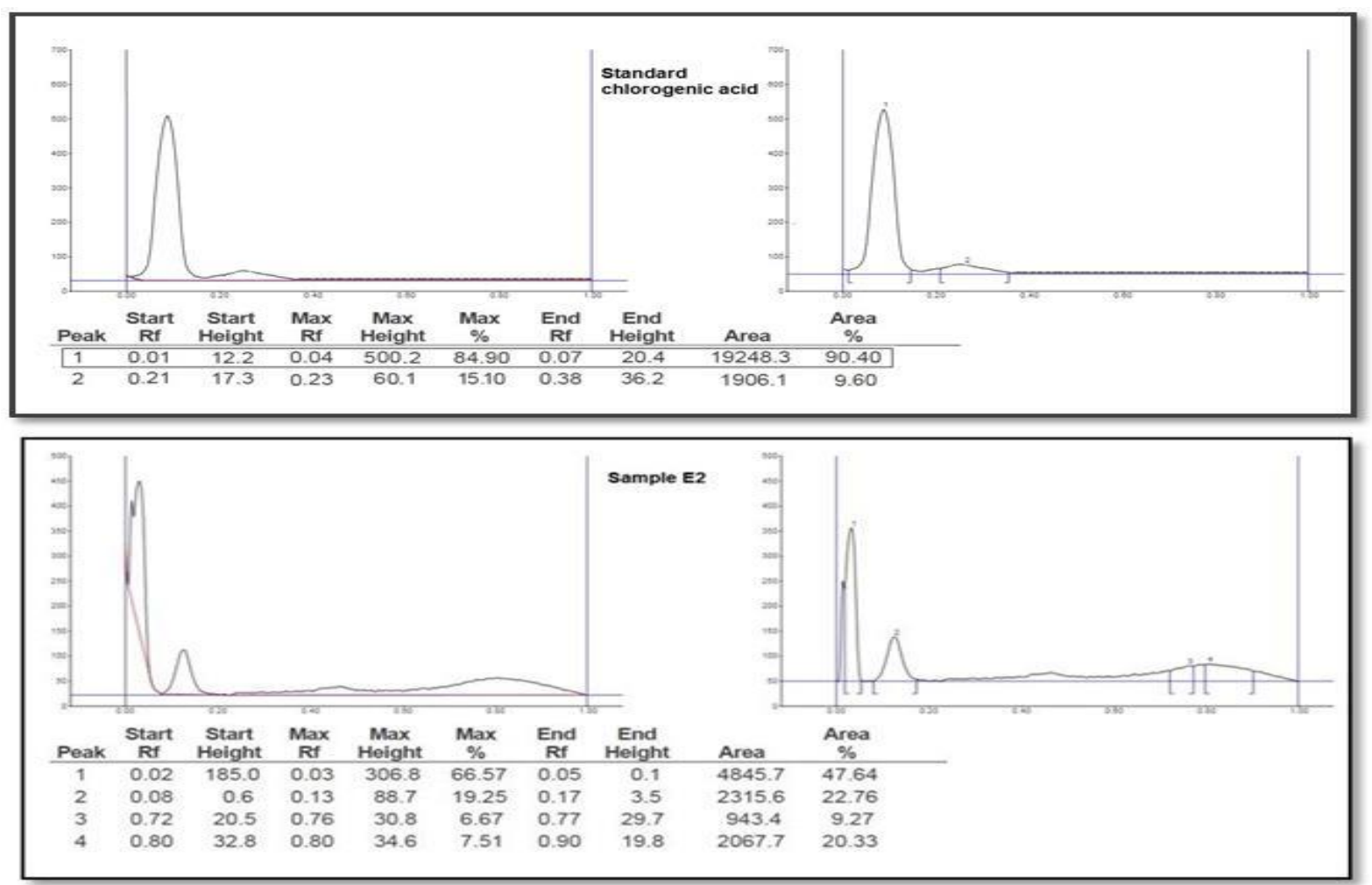

Figure 6. HPTLC chromatogram of standard and sample E2 chlorogenic acid at 254nm.
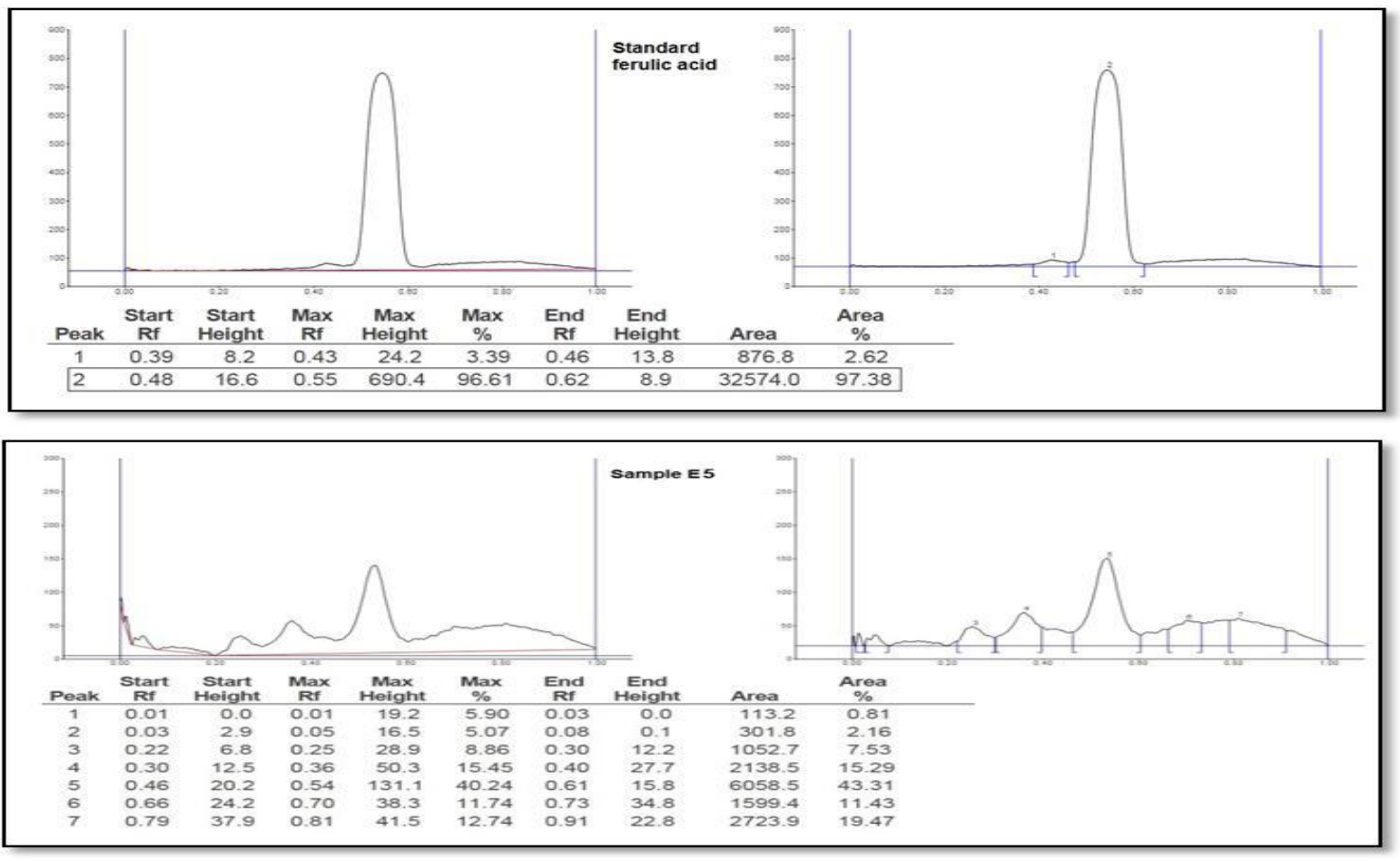

Figure 7. HPTLC chromatogram of standard and sample E5 ferulic acid at 254nm. 

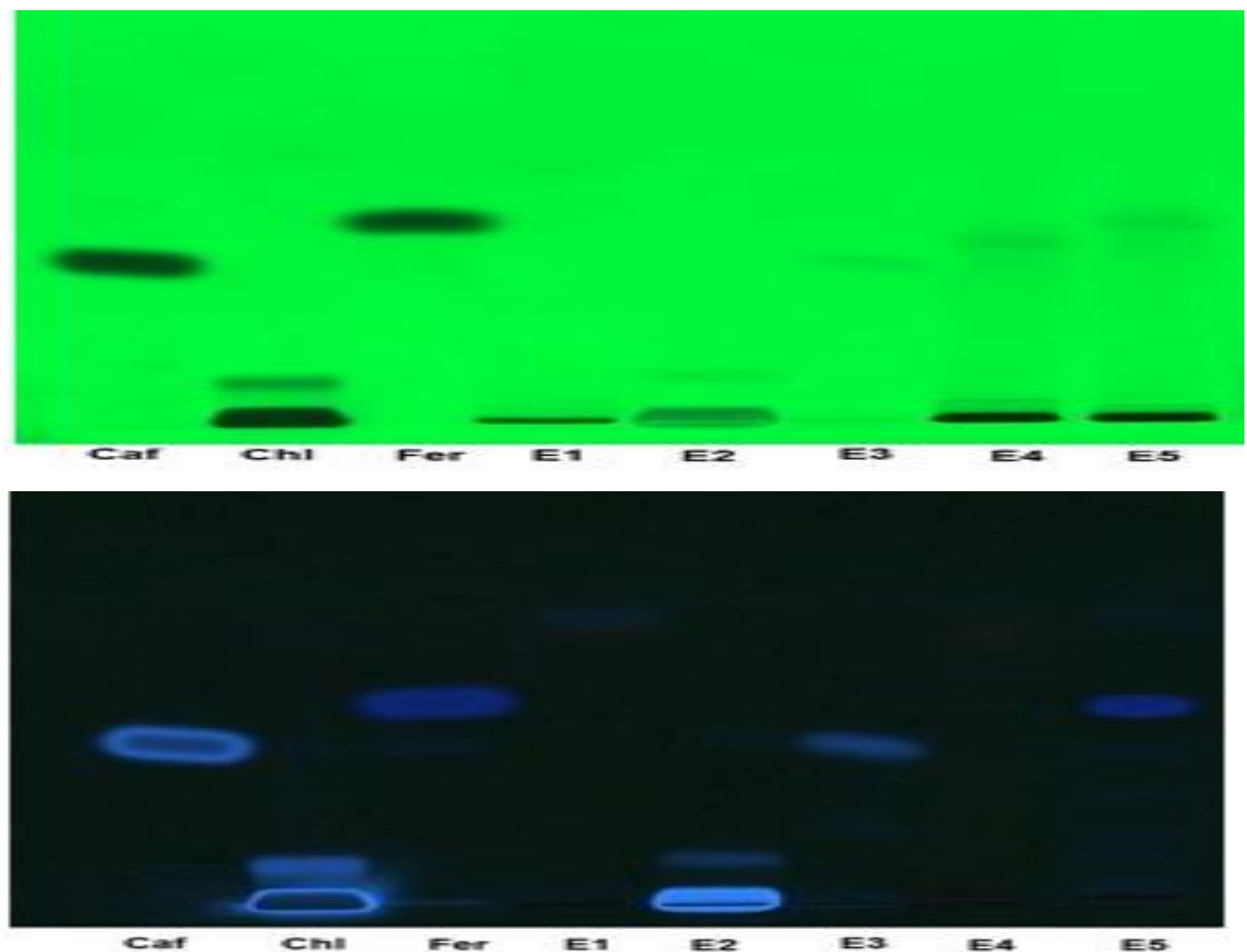

Figure 8 .HPTLC plates for standards and sample phenolic acids in E2, E3 and E5 at 254nm (above) and 366nm (below). Caf= caffeic acid, Chl= chlorogenic acid, Fer= ferulic acid, samples E1 to E5.

Table 3. Retention times of the standard phenolic acids and the concentration of sample phenolic acids at standard retention time.

\begin{tabular}{|l|c|c|c|}
\hline \hline \multicolumn{1}{|c|}{ Phenolic acid } & Standard RT & Sample conc. (mg/g plant) & Sample \\
\hline Caffeic acid & 14.000 & 0.3407 & E3 \\
\hline Chlorogenic acid & 13.400 & 0.3640 & E2 \\
\hline Ferulic acid & 13.756 & 13.11 & E5 \\
\hline
\end{tabular}

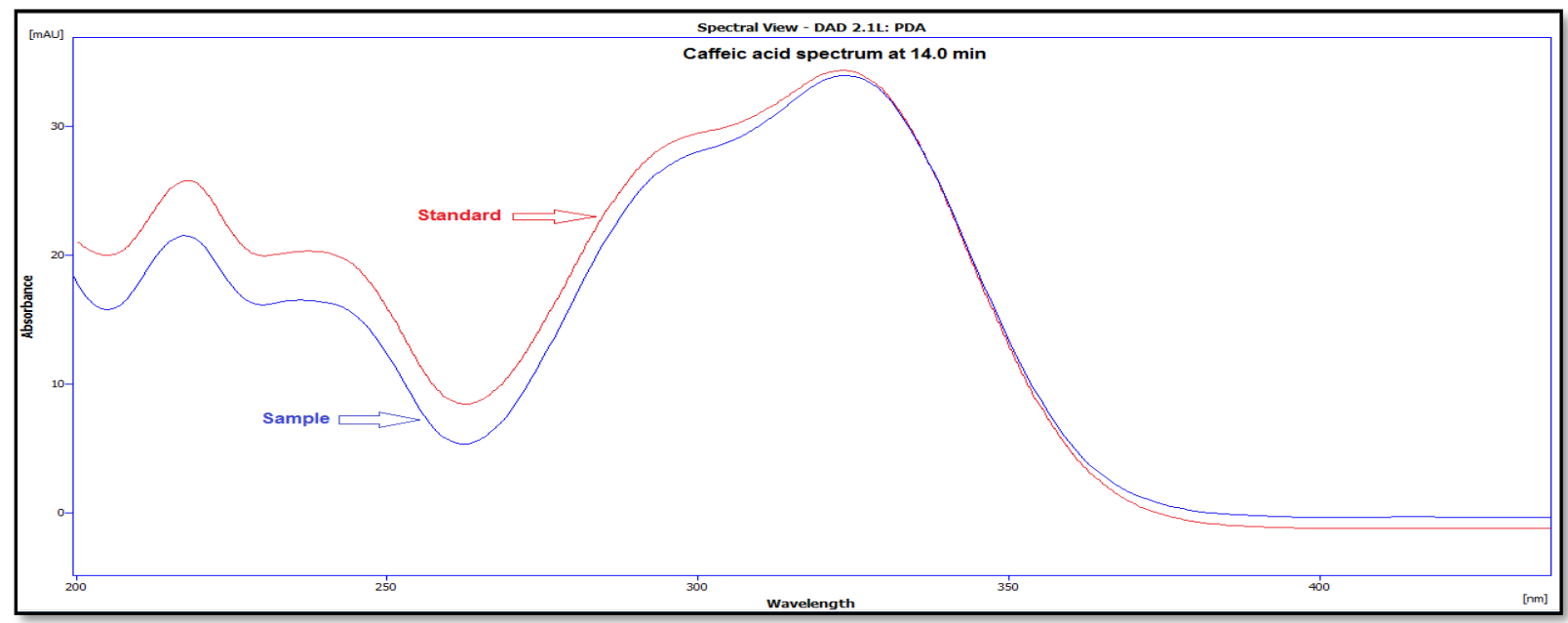

Figure 9. UV spectroscopy of standard and sample caffeic acid at $24.2 \mathrm{~min}$. 


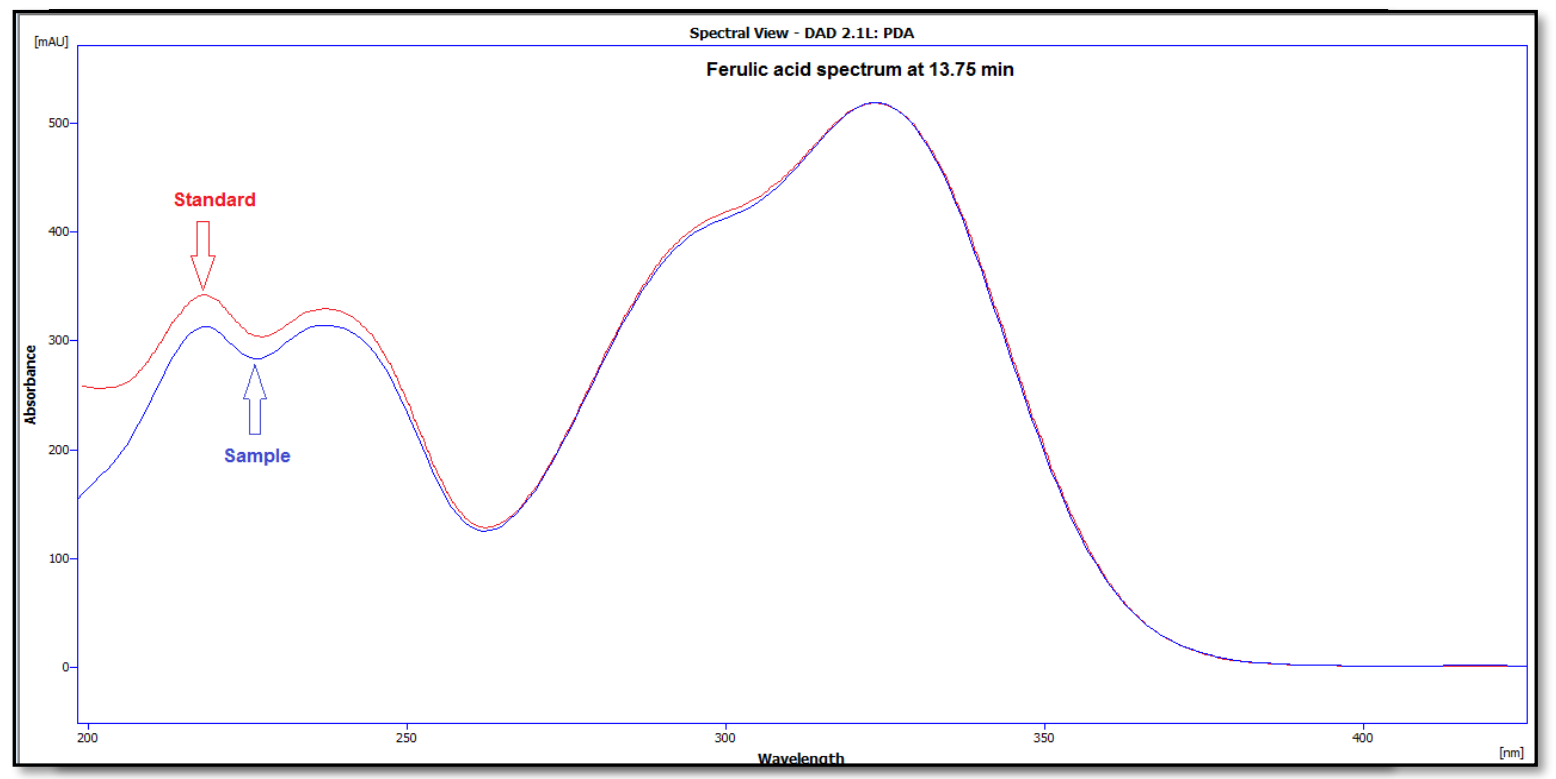

Figure 10. UV spectroscopy of standard and sample chlorogenic acid at 13.4min.

\section{Discussion}

Among many phytochemicals, Capparis spinosa had been reported to contain various type phenolic acids ${ }^{(8)}$. Polyphenolic acids are secondary metabolites with antioxidant properties that allow the plant to survive under stressful conditions ${ }^{(16)}$. In the present study, the positive preliminary result for the presence of phenolic acids in ethyl acetate fraction was followed by implication of chromatographic techniques to identify the nature of these acids. Three phenolic acids (caffeic, chlorogenic and ferulic) were used as standards in the subsequent analytic techniques. These reference acids are of particular concern due to their wellknown powerful antioxidant properties. Caffeic acid (3,4-dihydroxy cinnamic acid), chlorogenic acid (ester of caffeic acid and quinic acid) and ferulic acid (4-hydroxy-3-methoxycinnamic acid) are polyphenolic acids abundantly present in many plants and are derived from phenylalanine amino acid in the shikimic acid pathway during the synthesis of many polyphenolic phytochemicals like flavonoids ${ }^{(17)}$. The investigated phenolic acids were successfully identified in the ethyl acetate fraction of the plant extract according to the different polarities offered by chloroform:acetone:formic acid (75:16.5:8.5) as a mobile phase. Identification was based on observing separated spots in the ethyl acetate fraction that match in position the spots of standard phenolic acids, such results encourage subsequent isolation of these acids for qualitative and quantitative analysis by different chromatographic techniques. Preparative TLC resulted in the isolation of five distinct bands which were marked as sample E1 to E5. To identify whether the investigated acids were present in these samples, qualitative TLC analysis was performed and revealed the presence of caffeic acid in sample
E3, chlorogenic acid in sample E2 and ferulic acid in sample $\mathrm{E} 5$ by matching the $\mathrm{R}_{\mathrm{f}}$ values of sample spot with that of standard spot. The number of free hydroxyl groups in the structure of these acids is varying. It was 2 in ferulic acid, 3 in caffeic acid and 5 in chlorogenic acid. In addition, ferulic acid contains a methoxy group that renders the molecule highly less polar. In this context, the polarities of these acids were inversely proportionate with their $\mathrm{R}_{\mathrm{f}}$ values; the highest value was for ferulic acid and the lowest was for chlorogenic acid as shown in the results of TLC and HPTLC analysis (Tables 1 and 2). Qualitative analysis of isolated samples by HPLC also supported the results obtained by TLC and HPTLC when the UV spectra of these samples were compared with those of standard phenolic acids at the specified retention time of the standards. Quantitatively, the concentration of ferulic acid in sample E5 was much higher than those of chlorogenic acids in sample E2 and caffeic acid in sample E3 with a corresponding $13.11 \mathrm{mg}$, $0.3640 \mathrm{mg}$ and $0.3407 \mathrm{mg}$ per gram of plant, respectively (Table 3 ).

The powerful antioxidant property of these acids was highly investigated and is related to their poly phenolic nature ${ }^{(18,19)}$, for this reasons some food manufacturers prefer the addition of these phenolic acids such as ferulic acid as natural antioxidant (20). These phenolic acids have promising medicinal use in oxidative stress, microbial infections, inflammations, thrombosis and cancer ${ }^{(21)}$. Ferulic acid, which by this study is occurring in valuable amount in Iraqi caper, has been reported that improve the treatment in patients with high cholesterol, coronary heart diseases, infertility. Furthermore, it has a protective role 
against tissue damage induced by chemotherapeutic drugs ${ }^{(22)}$

In conclusion, many Iraqi authors have reported that caper shrub is one of the folkloric medicinal plants in Iraq. The present work identified the presence of caffeic, chlorogenic and ferulic acids in Iraqi caper following standard chromatographic techniques.

\section{References}

1. Moghaddasian, B., Asli, Moghaddasian, D., Alaghemand, A., and Miahi, M.: Anthocyanin content in different parts of Capparis spinosa growing wild in Tafresh/Iran. Technical Journal of Engineering and Applied Sciences, 2013; 3(11): 938-941.

2. Bakshi, D.N.G., P. Sensarma and D.C. Pal.: A Lexicon of Medicinal Plants in India, 1999; (1): 360-365.

3. Rhizopoulou, S. and Paras G.: Development and structure of drought tolerant leaves of Mediterranean shrub Capparis spinosa L. Annales of Botany, 2003; 92: 377-383.

4. Naoual Saifi, Ghizlane Echchgadda, Jamal Ibijbijen: The morphological characterization of caper plant (Capparis ssp.) in North Morocco. Journal of Food, Agriculture and Environment, 2010, 8(2): 876-881.

5. Rezzan Aliyazicioglu, Ozan Emre Eyupoglu, Huseyin Sahin, Oktay Yildiz, Nimet Baltas: Phenolic components, antioxidant activity, and mineral analysis of Capparis spinosa $\mathrm{L}$. African Journal of Biotechnology, 2013; 12(47): 6643-6649.

6. Rodrigo M, Lazaro M, Alvarruiz A, Giner V. Composition of capers (Capparis spinosa): influence of cultivar, size and harvest date. $\mathbf{J}$ Food Sci, 1992; 57: 1152-1154.

7. Mariapia Argentieri, FrancescoMacchia, Francesco PaoloFanizzi, PinarosaAvato. Bioactive compounds from Capparis spinosa. Industrial Crops and Products, 2012; 36(1): 6569.

8. Zhuohong Xie, John W. Finley. Herbs and Spices in, Principles of Food Chemistry, 2018: 457-481.

9. Al-Snafi AE. Encyclopedia of the constituents and pharmacological effects of Iraqi medicinal plants, 2015.

10. Selvamani, P., S. Latha, K. Elayaraja, P.S. Babu, J.K. Gupta, et al. Antidiabetic activity of the ethanol extract of Capparis sepiaria L leaves. Indian J Pharm Sci, 2008; 70(3): 37880.
11. N Aghel; I Rashidi; A Mombeini. Hepatoprotective Activity of Capparis spinosa Root Bark Against $\mathrm{CCl}_{4}$ Induced Hepatic Damage in Mice. Iranian Journal of Pharmaceutical Research, 2007; 6(4): 285-290.

12. Ephraim Philip Lansky, Helena Maaria Paavilainen, Shifra Lansky: Traditional Herbal Medicines for Modern Times: Caper The Genus Capparis. Taylor \& Francis Group, LLC, CRC press, 2014.

13. Sindhu Mathew; Tanya Abraham: Ferulic Acid: An Antioxidant Found Naturally in Plant Cell Walls and Feruloyl Esterases Involved in its Release and Their Applications. Critical Reviews in Biotechnology, 2004; 24(2-3):5983.

14. Bonina F., Puglia C., Ventura D., Aquino R., Tortora S., Sacchi A., Saija A., Tomaino A., Pellegrino M.L, and de Caprariis P. In vitro antioxidant and in vivo photoprotectiveffects of a lyophilized extract of Capparis spinosa L. buds. j. Cosmet. Sci., 2002; 53: 321-335.

15. Rimjhim Sheel, Kumari Nisha and Jainendra Kumar. Preliminary Phytochemical Screening of Methanolic Extract of Clerodendron infortunatum. IOSR Journal of Applied Chemistry, 2014; 7(1): 10-13.

16. MartinaDi Ferdinando, CeciliaBrunetti, Giovanni Agati, MassimilianoTattini: Multiple functions of polyphenols in plants inhabiting unfavorable Mediterranean areas. Environmental and Experimental Botany, 2014; 103: 107-116.

17. José Dzíaz, A. Ros Barceló and F. Merino De Cáceres: Changes in shikimate dehydrogenase and the end products of the shikimate pathway, chlorogenic acid and lignins, during the early development of seedlings of Capsicum annuum. The New Phytologist, 1997; 136(2): 183-188.

18. Yuki Sato,Shirou Itagaki,Toshimitsu Kuroka wa , Jiro Ogura, Masaki Kobayashi, ,Takeshi Hirano, Mitsuru Sugawara, Ken Iseki: In vitro and in vivo antioxidant properties of chlorogenic acid and caffeic acid. International Journal of Pharmaceutics, 2011; 403(1-2): 136-138.

19. Graf E. Antioxidant potential of ferulic acid. Free Radic Biol Med., 1992; 13(4):43548.

20. Srinivasan M, Sudheer AR, Menon VP. Ferulic Acid: therapeutic potential through its antioxidant property. J Clin Biochem Nutr., 2007; 40(2):92-100. 
21. Camelia Papuc, Gheorghe V. Goran, Corina N. Predescu, Valentin Nicorescu, and Georgeta Stefan: Plant Polyphenols as Antioxidant and Antibacterial Agents for Shelf-Life Extension of Meat and Meat Products: Classification, Structures, Sources, and Action Mechanisms.
Comprehensive Reviews in Food Science and Food Safety, 2017; 16: 1243- 1268.

22. Ou S., Kwok K-C.: Ferulic acid: pharmaceutical functions, preparation and applications in foods. J Sci Food Agric., 2004; 84(11):1261-1269.

Baghdad Iraqi Journal Pharmaceutical Sciences by bijps is licensed under a Creative Commons Attribution 4.0 International License. Copyrights $\bigodot 2015$ College of Pharmacy - University of Baghdad. 